Disclosure of Interests: None declared

DOI: 10.1136/annrheumdis-2019-eular.4411

\section{AB0291D $\quad$ PREDICTORS OF NEW BONE EROSION IN RHEUMATOID ARTHRITIS PATIENTS RECEIVING CSDMARDS: ANALYSIS OF DATA FROM THE DRIVE AND DESIRABLE STUDIES}

Tsutomu Takeuchi ${ }^{1}$, Satoshi Soen ${ }^{2}$, Naoki Ishiguro ${ }^{3}$, Hisashi Yamanaka ${ }^{4}$, Sakae Tanaka ${ }^{5}$, Makiko Kobayashi ${ }^{6}$, Naoki Okubo ${ }^{6}$, Takaya Nitta ${ }^{6}$, Yoshiya Tanaka ${ }^{7}{ }^{1}$ Keio University, Tokyo, Japan; ${ }^{2}$ Nara Hospital, Kinki University School of Medicine, Ikoma, Japan; ${ }^{3}$ Nagoya University, Nagoya, Japan; ${ }^{4}$ Tokyo Women's Medical University, Tokyo, Japan; ${ }^{5}$ The University of Tokyo, Tokyo, Japan; ${ }^{6}$ Daiichi Sankyo Co., Ltd., Tokyo, Japan; ${ }^{7}$ University of Occupational and Environmental Health, Kitakyusyu, Japan

Background: Suppression of joint destruction is an important target for the treatment of rheumatoid arthritis (RA). Most previous studies have proposed prediction models for joint destruction to detect the risk of rapid radiographic progression (change in $\mathrm{mTSS} \geq 5$ ). As joint destruction progresses irreversibly, even slight progression of joint destruction might impact the prognosis. Therefore, our study focused on the onset of new bone erosion in RA patients.

Objectives: To clarify predictors for new bone erosion in RA patients treated with csDMARDs.

Methods: Predictive factors were analyzed using data from the placebo groups of the DRIVE [1] and DESIRABLE [2] studies, which were 12month, randomized, double-blind, phase 2 and 3 trials for evaluating the efficacy of denosumab in RA patients. New bone erosion was defined as change from baseline in erosion score (ES) $\geq 1.0$ at 12 months, which was assessed as "progressed" by two readers. In addition to newly emerging erosion, new bone erosion also included enlargement of erosion size which is the result of new erosion at a site adjacent to an existing bone erosion. To evaluate predictors for new bone erosion, a logistic regression model was applied. Significant predictors ( $p$ value of $<0.1$ ) were selected from the univariate analysis and one variable from each correlated pair that showed significance was removed. Multivariate analyses were performed using the selected predictors.

Results: In a total of 306 patients, baseline DAS28-CRP (mean \pm SD) was $3.58 \pm 1.03$. New bone erosion was observed in 90 patients $(29.4 \%)$

In the univariate analysis, female sex, anti-CCP antibody positivity, rheumatoid factor (RF) positivity, tender joint count $(T J C) \geq 6, C R P \geq 0.3 \mathrm{mg} / \mathrm{dL}$, erythrocyte sedimentation rate $(E S R) \geq 28 \mathrm{~mm} / \mathrm{h}$, and baseline $E S \geq 3$ were identified as significant predictors for new bone erosion. RF and ESR were not included in the multivariate analysis because they were strongly correlated with anti-CCP antibody and $\mathrm{CRP}$, respectively. In the multivariate analyses, female sex, anti-CCP antibody positivity, TJC $\geq 6$, $\mathrm{CRP} \geq 0.3 \mathrm{mg} / \mathrm{dL}$, and baseline $\mathrm{ES} \geq 3$ were identified as predictors for the development of new bone erosion.

Abstract AB0291D Table 1. Univariate and multivariate analyses for a change in $E S \geq 1.0$

\begin{tabular}{|c|c|c|c|c|c|c|}
\hline \multirow{2}{*}{ Variables } & & \multirow[b]{2}{*}{ Reference } & \multicolumn{2}{|c|}{ Univariate } & \multicolumn{2}{|c|}{ Multivariate } \\
\hline & & & $\begin{array}{c}\text { Odds } \\
\text { ratio }\end{array}$ & $P$ value & $\begin{array}{l}\text { Odds } \\
\text { ratio }\end{array}$ & $P$ value \\
\hline Sex & Female & Male & 1.78 & 0.089 & 1.85 & 0.097 \\
\hline Age & $\geq 65$ years & $<65$ years & 0.79 & 0.423 & & \\
\hline $\begin{array}{l}\text { Duration of } \\
\text { disease }\end{array}$ & $\geq 3$ years & $<3$ years & 1.06 & 0.844 & & \\
\hline Anti-CCP antibody & Positive & Negative & 5.95 & $<0.001$ & 4.01 & $<0.001$ \\
\hline RF & Positive & Negative & 2.67 & $<0.001$ & & \\
\hline Glucocorticoid use & Yes & No & 0.99 & 0.963 & & \\
\hline TJC & $\geq 6$ & $<6$ & 1.66 & 0.047 & 1.70 & 0.060 \\
\hline Swollen joint count & $\geq 10$ & $<10$ & 1.26 & 0.353 & & \\
\hline CRP & $\geq 0.3 \mathrm{mg} / \mathrm{dL}$ & $\begin{array}{c}<0.3 \mathrm{mg} / \\
\mathrm{dL}\end{array}$ & 2.84 & $<0.001$ & 2.02 & 0.013 \\
\hline ESR & $\geq 28 \mathrm{~mm} / \mathrm{h}$ & $<28 \mathrm{~mm} / \mathrm{h}$ & 2.08 & 0.007 & & \\
\hline Baseline ES & $\geq 3$ & $<3$ & 3.32 & $<0.001$ & 2.29 & 0.005 \\
\hline Study & DESIRABLE & DRIVE & 1.16 & 0.602 & & \\
\hline
\end{tabular}

Conclusion: In RA patients whose disease activity was controlled on csDMARDs, positive anti-CCP antibody/RF status, elevated CRP/ESR levels, baseline $E S \geq 3, T J C \geq 6$ and female sex were identified as predictors for new bone erosion.

\section{REFERENCES}

[1] Takeuchi T, et al. Ann Rheum Dis 2016;75:983-90

[2] NCT01973569 (Takeuchi T, et al: in submission)

Disclosure of Interests: Tsutomu Takeuchi Grant/research support from: Astellas Pharma Inc, Chugai Pharmaceutical Co, Ltd., Daiichi Sankyo Co., Ltd., Takeda Pharmaceutical Co., Ltd., AbbVie GK, Asahikase Pharma Corp., Mitsubishi Tanabe Pharma Co., Pfizer Japan Inc., Eisai Co., Ltd., AYUMI Pharmaceutical Corporation, Nipponkayaku Co. Ltd. Novartis Pharma K.K., Grant/research support from: AbbVie, Asahi Kasei, Astellas, AstraZeneca, AYUMI, Bristol-Myers Squibb, Chugai, Daiichi Sankyo, Eisai, Eli Lilly Japan, Janssen, Mitsubishi Tanabe, Nippon Kayaku, Novartis, Pfizer Japan Inc, Taiho, Taisho Toyama, Takeda, Teijin, Grant/research support from: Astellas Pharma Inc., Bristol Myers Squibb, Chugai Pharmaceutical Co., Ltd., Mitsubishi Tanabe Pharma Co., Pfizer Japan Inc., Santen Pharmaceutical Co., Ltd., Takeda Pharmaceutical Co., Ltd., Teijin Pharma Ltd., AbbVie GK, Asahi Kasei Pharma Corp., Taisho Toyama Pharmaceutical Co., Ltd., SymBio Pharmaceuticals Ltd., Janssen Pharmaceutical K.K., Celltrion Inc., Nipponkayaku Co. Ltd., and UCB Japan, Consultant for: Astra Zeneca K.K. Eli Lilly Japan K.K., Novartis Pharma K.K., Mitsubishi Tanabe Pharma Co., Abbivie GK, Nipponkayaku Co.Ltd, Janssen Pharmaceutical K.K. Astellas Pharma Inc., Taiho Pharmaceutical Co. Ltd., Chugai Pharmaceutical Co. Ltd., Taisho Toyama Pharmaceutical Co. Ltd., GlaxoSmithKline K.K., UCB Japan Co. Ltd., Consultant for: AbbVie, Asahi Kasei, Astellas, AstraZeneca, AYUMI, Bristol-Myers Squibb, Chugai, Daiichi Sankyo, Eisai, Eli Lilly Japan, Janssen, Mitsubishi Tanabe, Nippon Kayaku, Novartis, Pfizer Japan Inc, Taiho, Taisho Toyama, Takeda, Teijin, Consultant for: Astra Zeneca K.K., Eli Lilly Japan K.K., Novartis Pharma K.K., Mitsubishi Tanabe Pharma Co., Asahi Kasei Medical K.K., AbbVie GK, Daiichi Sankyo Co., Ltd., Bristol Myers Squibb, and Nipponkayaku Co. Ltd., Speakers bureau: Astellas Pharma Inc., Bristol Myers Squibb, Chugai Pharmaceutical Co., Ltd., Mitsubishi Tanabe Pharma Co., Pfizer Japan Inc., Santen Pharmaceutical Co., Ltd., Takeda Pharmaceutical Co., Ltd., Teijin Pharma Ltd., AbbVie GK, Asahi Kasei Pharma Corp., Taisho Toyama Pharmaceutical Co., Ltd., SymBio Pharmaceuticals Ltd., Janssen Pharmaceutical K.K., Celltrion Inc., Nipponkayaku Co. Ltd., and UCB Japan, Speakers bureau: AbbVie, Asahi Kasei, Astellas, AstraZeneca, AYUMI, Bristol-Myers Squibb, Chugai, Daiichi Sankyo, Eisai, Eli Lilly Japan, Janssen, Mitsubishi Tanabe, Nippon Kayaku, Novartis, Pfizer Japan Inc, Taiho, Taisho Toyama, Takeda, Teijin, Speakers bureau: AbbVie GK., Bristol-Myers K.K., Chugai Pharmaceutical Co. Ltd., Mitsubishi Tanabe Pharma Co., Pfizer Japan Inc., Astellas Pharma Inc, Diaichi Sankyo Co. Ltd., Eisai Co. Ltd., Sanofi K. K., Teijin Pharma Ltd., Takeda Pharmaceutical Co. Ltd., Novartis Pharma K.K., Satoshi Soen Grant/research support from: Chugai Pharmaceutical Co,. Ltd., Diaichi Sankyo Co., Ltd., Speakers bureau: Asahi Kasei Pharma Corp, Astellas Pharma Inc, Chugai Pharmaceutical Co, Ltd., Daiichi Sankyo Co., Ltd., Eli Lilly Japan K.K., Eisai Co., Ltd. Ono Pharmaceutical CO., Ltd., Takeda Pharmaceutical Co., Ltd., Pfizer., Naoki Ishiguro Grant/research support from: AbbVie, Asahi Kasei, Astellas, Chugai, Daiichi-Sankyo, Eisai, Kaken, Mitsubishi Tanabe, Otsuka, Pfizer, Takeda, and Zimmer Biomet, Consultant for: Ono, Speakers bureau: Astellas, Bristol-Myers Squibb, Daiichi-Sankyo, Eli Lilly, Pfizer, and Taisho Toyama, Hisashi Yamanaka Grant/research support from: AbbVie, Eisai, Bristol-Meyers, Novartis, Behringer, Astellas, Kaken, Nippon-Shinyaku, Pfizer, UCB, Ayumi, Ono, Daiichi-Sankyo, Taisyo-Toyama, Takeda, Tanabe-Mitsubishi, Chugai, Teijin Pharma, Torii, YLbio, Speakers bureau: Bristol-Meyers, Astellas, Pfizer, Daiichi-Sankyo, Takeda, Tanabe-Mitsubishi, Chugai, Teijin Pharma, YLbio, Sakae Tanaka Grant/ research support from: KYOCERA Corporation and Asahi Kasei Corporation, Consultant for: Amgen Astellas BioPharma K.K., KYOCERA Corporation, Pfizer and Daiichi Sankyo Co., Ltd., Speakers bureau: Asahi Kasei Corporation, Astellas Pharma Inc, Ayumi Pharmaceutical Corporation, Eisai Co., Ltd., Ono Pharmaceutical Co., Ltd., Daiichi Sankyo Co., Ltd, Taisho Toyama Pharmaceutical Co., Ltd., Mitsubishi Tanabe pharma Corporation, Chugai Pharmaceutical Co., Ltd., Teijin Pharma Ltd., Eli Lilly, Hisamitsu Pharmaceutical Co, Inc., Pfizer, Bristol-Myers., Makiko Kobayashi Employee of: Daiichi Sankyo Co., Ltd., Naoki Okubo Employee of: Daiichi Sankyo Co., Ltd., Takaya Nitta Employee of: Daiichi Sankyo Co., Ltd., Yoshiya Tanaka Grant/research support from: Abbvie, Astellas, Bristol-Myers Squibb, Chugai, Daiichi-Sankyo, Eisai, 
Mitsubishi-Tanabe, MSD, Ono, Taisho-Toyama, Takeda, Speakers bureau: Abbvie, Asahi-kasei, Astellas, Bristol-Myers Squibb, Chugai, Daiichi-Sankyo, Eli Lilly, Eisai, Glaxo-Smithkline, Janssen, Mitsubishi-Tanabe, Novartis, Pfizer Japan Inc, Sanofi, Takeda, UCB, YL Biologics DOI: 10.1136/annrheumdis-2019-eular.4562

\section{AB0291E THE EFFECT OF HUMAN UMBILICAL CORD MESENCHYMAL STEM CELLS-DERIVED EXOSOMES ON CHEMOKINES IN COLLAGEN-INDUCED ARTHRITIS RATS}

Ping He. Shanxi Academy of Medical Sciences Shanxi Dayi Hospital, Taiyuan, China

Background: Umbilical cord mesenchymal stem cells (UCMSC) derived exosomes could simulate the function of MSC and avoid the limitations of MSC, which is being hotspot in the research of rheumatoid arthritis (RA) treatment. Chemokines can recruit inflammatory cells and osteoclasts in inflammatory joints, and participate in the synovial inflammation and bone destruction of RA. The mechanisms of UCMSC- derived exosomes on chemokines have less understood in $R A$

Objectives: The aim of this study was to investigate the effect of UCMSC and UCMSC-derived exosomes on the chemokines CCL2, CXCL10 and CXCL12 in CIA rats.

Methods: Human umbilical cord mesenchymal stem cells (UCMSCs) were cultured in vitro and separated using a differential centrifugation methods. The CIA rats model was set up by freund's complete adjuvant and type II collagen, then randomly divided into control, CIA, MTX, UCMSCs, UCMSCs exosomes low and high concentration groups. Rats in UCMSCs group were injected in double ankle joint with UCMSCs $2 \times 10^{6} / \mathrm{L}$ weekly for 3 weeks. Rats in UCMSCs exosomes low and high group were

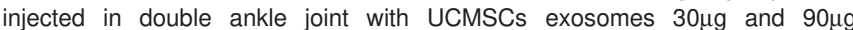
weekly for 3 weeks, respectively. Rats in MTX group were given intraperitoneal injection with MTX $(0.9 \mathrm{mg} / \mathrm{kg})$ weekly for 3 weeks. Serum concentrations of CCL2 and CXCL10 were detected by flow cytometry. CXCL12 serum level was tested by enzyme-linked immunosorbent assay (ELISA). The protein expressions of CCL2, CXCL10 and CXCL12 in synovial tissue were detected by immunohistochemistry. CCL2, CXCL10 and CXCL12 mRNA levels in synovial joint and spleen were measured by reverse transcription-polymerase chain reaction (RT-PCR).

Results: Intra-articular injection of UCMSC exosomes decreased CCL2 and CXCL12 levels in serum and improved synovial hyperplasia and inflammatory cell infiltration in the CIA rats. UCMSC exosomes suppressed the protein expressions of CCL2, CXCL10, CXCL12 in synovial tissue. It also inhibited transcript levels of CCL2, CXCL10, CXCL12 in synovial tissue and spleen. UCMSC had similar effect on CCL2, CXCL10, CXCL12 in CIA. The high concentration group was more effective than the low concentration in preventing CCL2,CXCL10,CXCL12 protein expressions of synovial tissue and CCL2 transcript level of spleen. Conclusion: UCMSC exosomes alleviates synovial inflammation in CIA rats through suppression of CCL2, CXCL10, CXCL12 release. The inhibitory effect of on chemokines simulate UCMSC, their cell of origin, the high concentration was better than low concentration.

\section{REFERENCES}

[1] F. Djouad, V. Fritz, F. Apparailly, P.Reversal of the immunosuppressive properties of mesenchymal stem cells by tumor necrosis factor $\alpha$ in collagen-induced arthritis[J]. Arthritis Rheum., 52 (5) (2005), pp. 1595-1603.

[2] A. Augello, R. Tasso, S.M. Negrini, R. Cell therapy using allogeneic bone marrow mesenchymal stem cells prevents tissue damage in collageninduced arthritis[J]. Arthritis Rheum., 56 (4) (2007), pp. 1175-1186.

[3] Y. Liu, R. Mu, S. Wang, L. Long, Therapeutic potential of human umbilical cord mesenchymal stem cells in the treatment of rheumatoid arthritis[J]. Arthritis Res Ther., 12 (6) (2010), p. R210.

[4] Rani S,Ryan AE,Griffin MD, Ritter T.Mesenchymal stem cell-derived extracellular vesicles:toward cell-free therapeutic applications[J].Mol Ther,2015,23(5):8 12-823

[5] Szekanecz Z, Kim J, Koch AE. Chemokines and chemokine receptors in rheumatoid arthritis. Semin Immunol. 2003 Feb;15(1):15-21.

Disclosure of Interests: None declared

DOI: 10.1136/annrheumdis-2019-eular.7165

\section{Rheumatoid arthritis - comorbidity and clinical aspects}

\section{AB0292 EFFECTS OF ACETAMINOPHEN ON THE KIDNEY FUNCTIONS OF PAITIENTS WITH MUSCULOSKERLTAL DISEASE TREATED WITH LONG-TERM NONSTEROIDAL ANTI-INFRAMMATORY DRUG THERAPY}

Toshiaki Aizawa $^{1}$, Tetsuya Kawano ${ }^{1}$, Takeshi Kashiwagura ${ }^{2}$, Naohisa Miyakoshi ${ }^{3}$, Yoichi Shimada ${ }^{3} .{ }^{1}$ Kitaakita Municipal Hospital, Akita, Japan; ${ }^{2}$ Akita City Hospital, Akita, Japan; ${ }^{3}$ Akita University Graduate School of Medicine, Akita, Japan

Background: While nonsteroidal anti-inflammatory drugs (NSAIDs) are the most frequently used therapeutic agents, they are known to cause side effects, such as gastrointestinal disorders and kidney dysfunction. As the proportion of patients with chronic kidney disease (CKD) increases with age, dealing with NSAIDs requires particular care in areas with aging populations. However, in many cases, prescriptions are continued without any particular plan. Hence, the effects of acetaminophen (AAP), which does not cause kidney dysfunction, are being revisited. Opportunities are increasing for using formulations containing tramadol hydrochloride in patients with chronic pain or intravenous agents for perioperative pain management.

Objectives: In this study, we investigated the kidney functions of patients with musculoskeletal disease who had been using NSAIDs for a long time and examined the possibility of switching to AAP.

Methods: The subjects were 105 patients with musculoskeletal disease (42 men and 63 women) who were being treated as outpatients in the orthopedics department of our hospital and had been using NSAIDs for at least 3 months. They primarily had 5 musculoskeletal diseases, including degenerative osteoarthritis (OA), rheumatoid arthritis (RA), osteoporosis $(\mathrm{OP})$, polymyalgia rheumatica (PMR), and gout $(\mathrm{G})$. After checking their background characteristics, we measured their kidney functions and visual analogue scale (VAS) scores, and then switched them from NSAIDs to AAP. Kidney functions were evaluated by classifying CKD using glomerular filtration rate (eGFR) and urinary protein, and by using the CockcroftGault equation to calculate creatinine clearance (Ccr). The patients were given the NSAIDs that they had been taking for single use. Six months after the switch, we remeasured their kidney functions and VAS scores, and investigated whether they could continue using AAP and whether they had used NSAIDs.

Results: The patients' mean age at the time of switching from NSAIDs to AAP was 76 years, and their mean duration of NSAID use was 43 months. For the diseases, 63 patients had OA, 20 had RA, 14 had OP 6 had PMR, and 2 had G. Before the switch, the mean VAS score was $41.6 \mathrm{~mm}$ and mean eGFR was $67.0 \mathrm{~mL} / \mathrm{min} / 1.73 \mathrm{~m}^{2}$. On the basis of the eGFR, the CKD classification was G3 or higher in $38.1 \%$ of patients. The CKD classifications with the amounts of urinary protein added to the eGFR were as follows: green, $44.7 \%$; yellow, $33.0 \%$; orange, $14.6 \%$; and red, $7.8 \%$, with $55.4 \%$ classified as having CKD. By age, the proportions of patients with CKD based on eGFR and CKD classification were as follows, respectively: $0.0 \%$ and $12.5 \%$ for those in their $50 \mathrm{~s}, 16.7 \%$ and $25.0 \%$ for those in their $60 \mathrm{~s}, 29.3 \%$ and $48.8 \%$ for those in their $70 \mathrm{~s}$ and $59.5 \%$ and $69.0 \%$ for those in their $80 \mathrm{~s}$ and older. The mean AAP dose was $455 \mathrm{mg}$.

Six months after the switch, 69 patients had continuously used AAP without regular NSAID use. Of these patients, 13 had used NSAIDs for rescue purposes. Thirty-six patients had stopped using AAP, the most common reason being ineffectiveness (15 patients), although 9 patients did so because they no longer needed any analgesic. Three patients stopped using the drug owing to palpitations or other side effects, although none stopped because of liver dysfunction. Overall, the mean VAS score declined significantly as compared with before the switch, as did the mean eGFR. Of those who continued to use AAP, 56 patients who did not use any NSAIDs exhibited significantly lower mean VAS scores, but not a significant decline in mean eGFR.

Conclusion: The proportion of patients with CKD who were receiving long-term NSAID therapy was higher than that of the general population for all age groups. Halting NSAIDs and switching to AAP could help maintain kidney functions, which could continue to decline with NSAID use.

\section{REFERENCES}

[1] CKD guidebook;2012 